\title{
Clostridium perfringens septicemia in a long-beaked common dolphin Delphinus capensis: an etiology of gas bubble accumulation in cetaceans
}

\author{
Kerri Danil ${ }^{1, *}$, Judy A. St. Leger ${ }^{2}$, Sophie Dennison ${ }^{3}$, Yara Bernaldo de Quirós ${ }^{4}$, \\ Miriam Scadeng ${ }^{5}$, Erika Nilson ${ }^{2}$, Nicole Beaulieu ${ }^{1}$ \\ ${ }^{1}$ Marine Mammal \& Turtle Division, Southwest Fisheries Science Center, National Marine Fisheries Service, \\ National Oceanic and Atmospheric Administration, 8901 La Jolla Shores Drive, La Jolla, CA 92037, USA \\ ${ }^{2}$ Sea World San Diego, 500 Sea World Drive, San Diego, CA 92109, USA \\ ${ }^{3} 10$ Liberty Way no. 102, 851 Indiana Street no. 307, San Francisco, CA 94107, USA \\ ${ }^{4}$ Department of Biology, Woods Hole Oceanographic Institute, Woods Hole, MA 02543, USA \\ ${ }^{5}$ Center for Functional MRI, Department of Radiology, University of California at San Diego, La Jolla, CA 92093, USA
}

\begin{abstract}
An adult female long-beaked common dolphin Delphinus capensis live-stranded in La Jolla, California, USA, on July 30, 2012 and subsequently died on the beach. Computed tomography and magnetic resonance imaging revealed gas bubble accumulation in the vasculature, organ parenchyma, mandibular fat pads, and subdermal sheath as well as a gas-filled cavity within the liver, mild caudal abdominal effusion, and fluid in the uterus. Gross examination confirmed these findings and also identified mild ulcerations on the palate, ventral skin, and flukes, uterine necrosis, and multifocal parenchymal cavitations in the brain. Histological review demonstrated necrosis and round clear spaces interpreted as gas bubbles with associated bacterial rods within the brain, liver, spleen, and lymph nodes. Anaerobic cultures of the lung, spleen, liver, bone marrow, and abdominal fluid yielded Clostridium perfringens, which was further identified as type A via a multiplex PCR assay. The gas composition of sampled bubbles was typical of putrefaction gases, which is consistent with the by-products of $C$. perfringens, a gas-producing bacterium. Gas bubble formation in marine mammals due to barotrauma, and peri- or postmortem offgassing of supersaturated tissues and blood has been previously described. This case study concluded that a systemic infection of $C$. perfringens likely resulted in production of gas and toxins, causing tissue necrosis.
\end{abstract}

KEY WORDS: Cetacea $\cdot$ Clostridium · Delphinus capensis $\cdot$ Disease $\cdot$ Gas bubble $\cdot$ Gas gangrene $\cdot$ Marine mammals $\cdot$ Strandings

\section{INTRODUCTION}

Gas emboli can result from iatrogenic sources, barotrauma (Saukko \& Knight 2004), off-gassing of supersaturated blood and tissues (Hamilton 2003), absorption of intestinal gas (Shaw et al. 1967), or gasproducing bacteria (Hart et al. 1983). Gas emboli in marine mammals were first reported in the liver, pancreas, and kidneys of spotted dolphins Stenella attenuata and spinner dolphins $S$. longirostris captured incidentally in tuna purse-seine operations. The etiology was hypothesized to be alveolar rupture due to violent respiratory movement associated with asphyxiation (Cowan \& Walker 1979). Several subsequent studies that reported gas emboli in cetaceans hypothesized that off-gassing of supersaturated blood and tissues is the mechanism for accumulation of intravascular and/or intraparenchymal gas. These 
studies included a beaked whale mass stranding associated with military exercises in the Canary Islands (Jepson et al. 2003, Fernández et al. 2005), hepatic and renal cavitations in UK cetaceans (Jepson et al. 2003, 2005), dysbaric osteonecrosis in sperm whales (Moore \& Early 2004), marine mammals incidentally killed at depth during fishing operations (Moore et al. 2009), and live-stranded dolphins (Dennison et al. 2012). In these cases, the suggested mechanism challenged the previous perception that marine mammals do not suffer decompression sickness. More recently, intravascular gas emboli were linked to barotrauma in 3 long-beaked common dolphins Delphinus capensis killed by an underwater detonation (Danil \& St. Leger 2011, St. Leger et al. 2011). All of these studies highlight the need to better understand the causes of gas bubble formation, and further investigations have been proposed, including analysis of gas bubble composition (Piantadosi \& Thalmann 2004).

Accordingly, gas sampling and analysis protocols for marine mammals have recently been developed (Bernaldo de Quirós et al. 2011, 2012a, 2013). Bernaldo de Quirós et al. (2012b) found that gas bubbles are more common in deeper-diving cetaceans and are mainly composed of $70 \%$ nitrogen and $30 \% \mathrm{CO}_{2}$, supporting the concept of decompression-related gas embolism in many stranded cetaceans.

Gas production by the bacteria Clostridium spp. in captive cetaceans, manatees, and pinnipeds has been briefly described in the literature, with some of these cases attributed to C. perfringens specifically. Although Clostridium spp. are the prevalent causative organisms of gas-forming infections, polymicrobial infections including Enterococcus, Enterobacter cloacae, Staphylococcus aureus, Bacteroides fragilis, Pseudomonas aeruginosa, and Escherichia coli have been reported in the human literature (Yang et al. 1996). C. perfringens is a Gram-positive, rod-shaped, spore-forming, anaerobic, oxygen-tolerant bacterium that is found in the soil, marine and freshwater sediment, and in the intestinal tract of humans and animals. It is a fermentive $\mathrm{H}_{2}$-producing bacterium (Rood \& Cole 1991) that is classified into 5 types (A, $\mathrm{B}, \mathrm{C}, \mathrm{D}, \mathrm{E})$ based on the production of 4 major toxins: alpha, beta, epsilon, and iota (McDonel 1980). Enterotoxin and beta 2 toxins can also be produced by all $C$. perfringens types but are not used in the classification scheme of this bacterium. C. perfringens type A produces an alpha toxin, which is a lecithinase (phospholipase) that causes lysis of red blood cells, myocytes, fibroblasts, platelets, and leukocytes (Revis 2011) and is known to play a major role in gas gangrene (Quinn et al. 2011). It has also been known to cause myositis, enterotoxemia, diarrhea, and hemorrhagic gastroenteritis in both humans and wildlife (Hirsh \& Biberstein 2004).

C. perfringens is part of the normal flora of marine mammal gastrointestinal (GI) tracts as can be seen by its isolation from the GI tracts of captive killer whales Orcinus orca, false killer whales Pseudorca crassidens, bottlenose dolphins Tursiops truncatus, and dwarf sperm whales Kogia sima (Walsh et al. 1994), as well as from wild hooded seals Cystophora cristata (Aschfalk \& Müller 2001), harbor porpoises Phocoena phocoena (Siebert et al. 2001), harbor seals Phoca vitulina (Siebert et al. 2007), and polar bears Ursus maritimus (Jores et al. 2008).

Brief descriptions of Clostridium spp. infections in captive marine mammals have been reported and include a presumptive clostridial enterotoxemia in O. orca (Griffin \& Goldsberry 1968), a gas-producing myositis in T. truncatus (Sweeney \& Ridgway 1975), clostridial myositis following intramuscular injections in O. orca, T. truncatus, and a California sea lion Zalophus californianus (Greenwood \& Taylor 1978), and a clostridial infection in a manatee that caused the side of the animal to swell and subsequently caused death (Caldwell \& Caldwell 1985). A localized $C$. perfringens infection that resulted in colonic rupture and subsequent death of a captive $Z$. californianus was more thoroughly described by Van Bonn et al. (1995). In addition, Buck et al. (1987) described the exogenous introduction of $C$. perfringens from pool water into the musculature of a captive $T$. truncatus via skin lacerations, which resulted in systemic gas gangrene and subsequent death of the animal. We present a case of gas emboli and parenchymal cavitations caused by $C$. perfringens septicemia, in a free-ranging marine mammal, using new techniques that include polymerase chain reaction (PCR), radiology, and gas analysis.

\section{MATERIALS AND METHODS}

On July 30, 2012, lifeguards reported a livestranded dolphin on the beach at Sea Lane Beach, La Jolla, California, USA $\left(32^{\circ} 50^{\prime} 8.5^{\prime \prime} \mathrm{N}, 117^{\circ} 16^{\prime}\right.$ $53.0^{\prime \prime} \mathrm{W}$ ), to the local marine mammal stranding network. The animal subsequently died on the beach and was placed in a refrigerator within $2 \mathrm{~h}$ postmortem. Magnetic resonance imaging (MRI), computed tomography (CT), and a gross necropsy examination were all performed within $24 \mathrm{~h}$ of death, with the animal refrigerated in between procedures. 
The CT scan was completed using a Siemens Emotion 6 scanner in helical mode, set at $110 \mathrm{kV}$ and $91 \mathrm{mAs}$, with the specimen placed in sternal recumbency within the gantry and acquired in 2 acquisitions, cranial half and caudal half. Images were acquired using $1.5 \mathrm{~mm}$ slice thickness and bone and tissue reconstruction algorithms. An MRI was acquired with a 3Tesla Discovery GE750 scanner using both fast spin echo and gradient echo sequences, with the specimen placed in sternal recumbency within the gantry and acquired in 1 acquisition.

Dorsal, lateral, and ventral blubber depths were collected along a vertical gradient beginning at the anterior insertion of the dorsal fin. Cervical blubber depth was collected just posterior to the blowhole. Gross examination involved visual inspection and collection of tissues from the brain, pituitary gland, heart, trachea, lungs, liver, kidney, bladder, spleen, tonsil, lymph nodes, skin, skeletal muscle, oropharynx, esophagus, stomach, pancreas, and intestines. Uterus and ovaries were examined but were not collected in formalin. All other collected tissues were fixed in $10 \%$ neutral buffered formalin, embedded in paraffin, sectioned at 4 to $7 \mathrm{~mm}$, stained with hematoxylin and eosin (HE), and examined microscopically. Select tissues demonstrating bacterial rods within clear spaces were additionally stained with Brown-Hopps stain to determine Gram-staining properties. Age was determined by examining growth layers in the teeth following the methods outlined by Danil \& Chivers (2007).

To quantify the abundance of gas in the specimen, a gas score was assigned (Bernaldo de Quirós et al. $2012 b)$. Ten gas samples were collected and analyzed from the mesenteric vasculature $(n=3)$, parietal peritoneum $(n=3)$, aorta $(n=3)$, and ambient air (control; $\mathrm{n}=1$ ) according to the methods outlined by Bernaldo de Quirós et al. (2012a).

Aerobic and anaerobic cultures were performed on lung, spleen, liver, bone marrow, and abdominal fluid. Samples collected at necropsy were inoculated onto blood agar and incubated at $37^{\circ} \mathrm{C}$ for 2 to $10 \mathrm{~d}$. Bacterial identification was performed via a Vitek ${ }^{\circledR}$ Microbial Identification System (Biomerieux). Isolates were evaluated for toxin typing of Clostridium perfringens via multiplex PCR (Meer \& Songer 1997).

\section{RESULTS}

The stranded dolphin was a $212.2 \mathrm{~cm}$ long, $16 \mathrm{yr}$ old, $85.5 \mathrm{~kg}$ adult female long-beaked common dolphin Delphinus capensis. Externally, the dolphin presented with a $1 \mathrm{~cm}$ diameter abscess on the fluke, 2 ventral skin ulcerations (each $3 \mathrm{~cm}$ long) extending into the blubber with secondary healing (Fig. 1a), a mild ulceration on the palate and the floor of the mouth, and fresh rake marks.
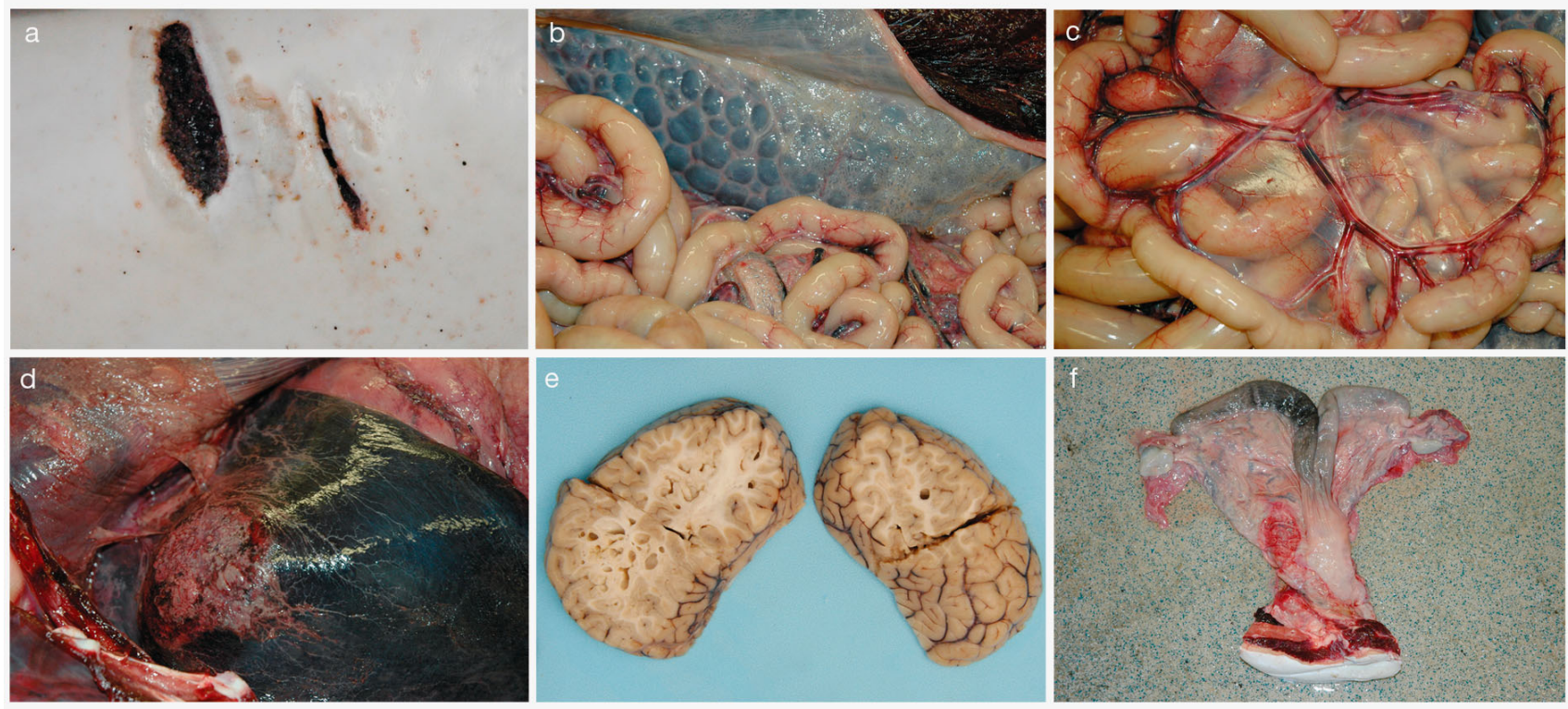

Fig. 1. Gross necropsy observations of a stranded adult female long-beaked common dolphin Delphinus capensis: (a) secondary healing of skin wounds, (b) gas bubbles in the visceral peritoneum of the kidney, (c) mesenteric gas emboli, (d) hepatic focal mass, (e) cavitations within cerebrum, (f) uterine necrosis 


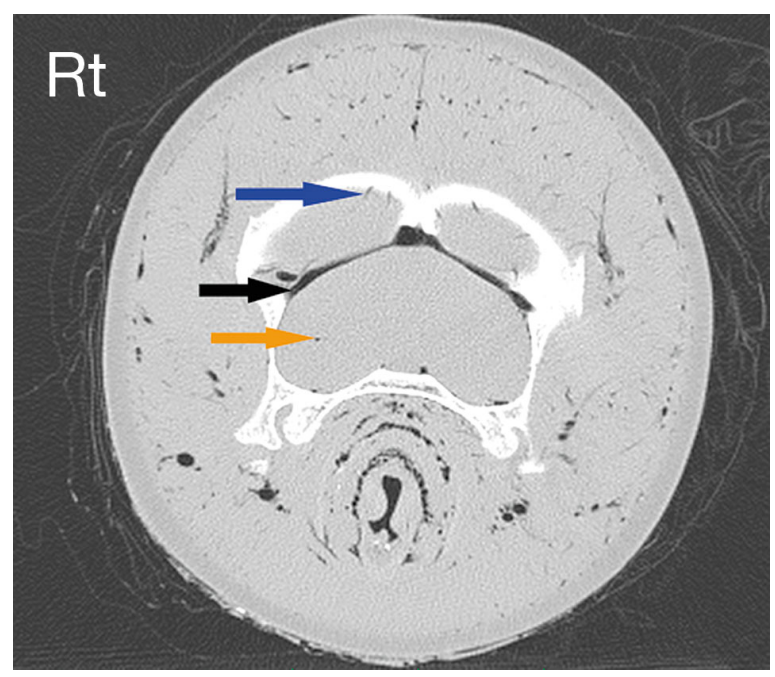

Fig. 2. Computed tomography (CT) image showing subarachnoid (black arrow), cerebral (blue arrow), and cerebellar vascular or parenchymal (orange arrow) gas accumulation in a stranded adult female long-beaked common dolphin Delphinus capensis. Rt: right side of body

\section{Radiology (CT and MRI)}

Diagnostic imaging revealed water in the blow hole, mild ascites, marked diffuse gas bubble accumulation in the vasculature with concurrent intracardiac, subarachnoid (Fig. 2), retroperitoneal, and peritoneal gas accumulations, and intestinal and hepatic pneumatosis. Specifically, vascular gas bubbles occurred in the aorta, cranial and caudal vena cava, pulmonary arteries and veins, coronary arteries, brachicephalic trunk and branching arteries, neural canal venous sinuses, and blood vessels of the meninges and cerebrum/cerebellum (Fig. 2), intercostal muscles, kidneys, hepatic portal vein, and the mesentery. The greatest intravascular accumulation was noted in the dorsal paraspinal musculature. Bubbles of gas were found in multiple organs: heart, eye, intestine, liver, spleen, and brain. The liver presented with a $4.4 \mathrm{~cm} \times 7 \mathrm{~cm} \times 5.3 \mathrm{~cm}$ focal mass in the left lobe (Fig. 3) and a $3.4 \mathrm{~cm}$ diameter, less well-defined mass in the right lobe. In addition, gas accumulation was evident bilaterally in the mandibular fat pads, throughout the melon, and diffusely throughout the subdermal sheath.

\section{Gross examination}

Dorsal, lateral, ventral, and cervical blubber thickness was $0.7,0.6,0.3$, and $0.9 \mathrm{~cm}$, respectively. All of these measures, except ventral, were below the

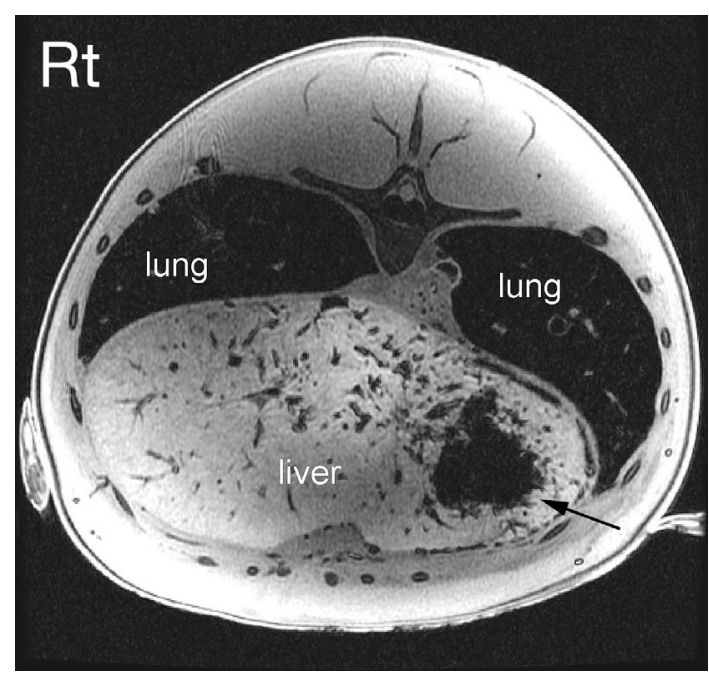

Fig. 3. Magnetic resonance image (MRI) demonstrates focal air-filled mass (black arrow) in the liver of a stranded adult female long-beaked common dolphin Delphinus capensis. Rt: right side of body

lower quartile of blubber thickness measures for previously stranded adult female $D$. capensis ( $\mathrm{n}=30$; authors' unpubl. data), demonstrating poor body condition. Gas bubbles with an estimated volume ranging from 0.1 to $2 \mathrm{ml}$ were visible in the subdermal sheath, parietal peritoneum, visceral peritoneum of the kidney (Fig. 1b), splenic vasculature, mesenteric vasculature (Fig. 1c), calvarial vasculature on the inner surface of the skull, and liver (Fig. 1d). Gross exam also revealed froth in the bronchi, ascites, and cavitations within the white matter of the brain (Fig. 1e). The spleen was enlarged and weighed $158 \mathrm{~g}$. This is above the $90 \%$ quantile for previously weighed spleens from stranded adult $D$. capensis ( $\mathrm{n}=28$; authors' unpubl. data). The serosal surface of the left and right uterine horns was black and gray, respectively (Fig. 1f). Upon dissection, black striations within the folds of the endometrium were visible in both uterine horns. The left uterine horn appeared slightly wider, and a regressing corpus luteum (16.1 mm diameter) was present on the left ovary. In total, there were 4 corpora albicantia on the left ovary and 1 on the right.

\section{Histological findings}

Histopathology revealed multifocal intraparenchymal cavitations in the brain, which were clear spaces with no epithelial lining. Loosely arranged colonies of large bacterial rods were found within these spaces, within and around adjacent vessels, and scattered within the adjacent parenchyma (Fig. 4). Gram stains 
of brain tissue demonstrated Gram-positive staining of the bacterial rods (Fig. 5). The pituitary gland had a focally extensive area of necrosis with central bacterial colonies as seen in the brain. The liver demonstrated a severe diffuse necrotizing and hemorrhagic hepatitis with abundant bacterial rods and abundant, variably sized, irregular-shaped cavitations containing clear spaces or edema fluid (Fig. 6). A moderate and acute necrotizing splenitis was observed. Lymph nodes demonstrated moderate multifocal single cell necrosis, bacterial thrombi, and occasional parenchymous gas bubbles. Mild to moderate dilation, congestion, and gas within both submucosal and mucosal vessels of

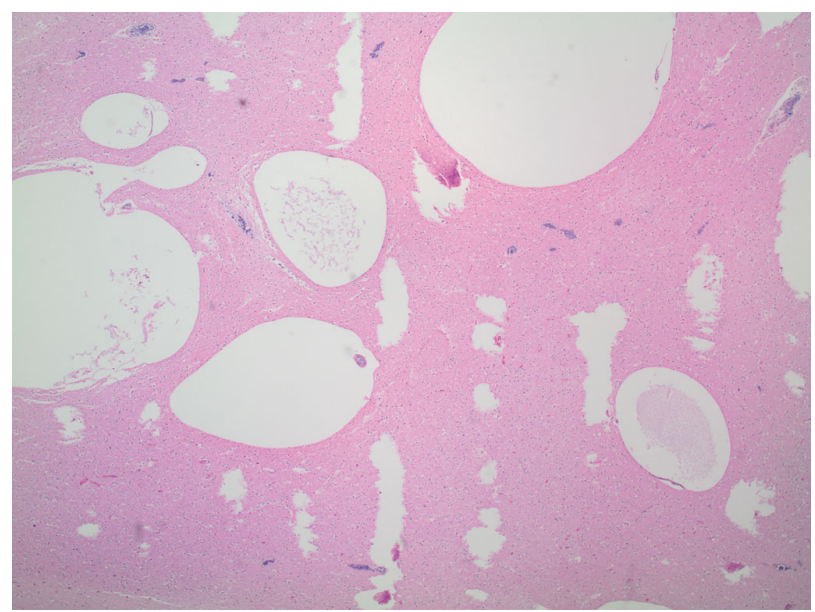

Fig. 4. Clear spaces within the brain parenchyma of a stranded adult female long-beaked common dolphin Delphinus capensis represent emboli (bubbles) with frequent occurrence of basophilic bacterial rods at the margins. Magnification is $40 x$

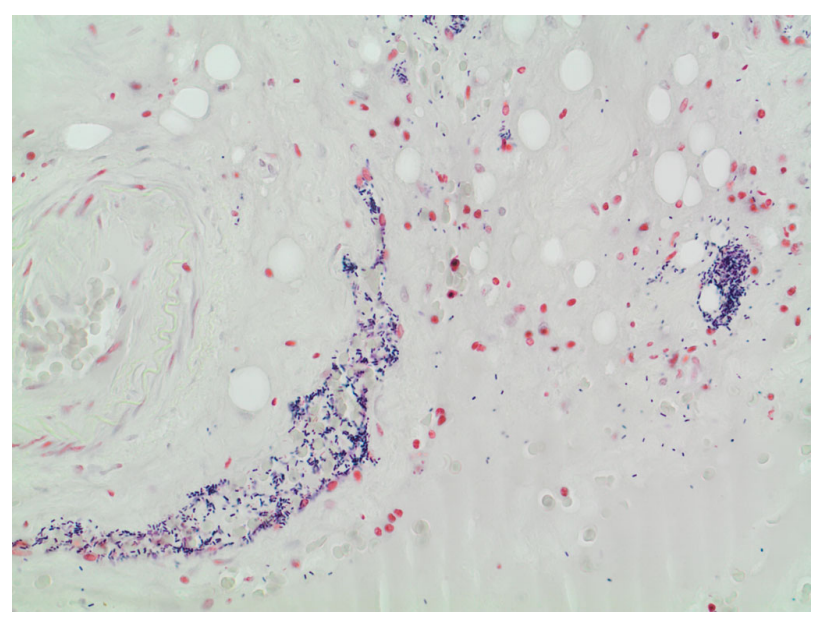

Fig. 5. Gram stain of brain tissue of a stranded adult female long-beaked common dolphin Delphinus capensis reveals abundant Gram-positive rods associated with both vessels and parenchyma. Note the good state of preservation of the tissue as evidence against autolysis. Magnification is $400 \times$

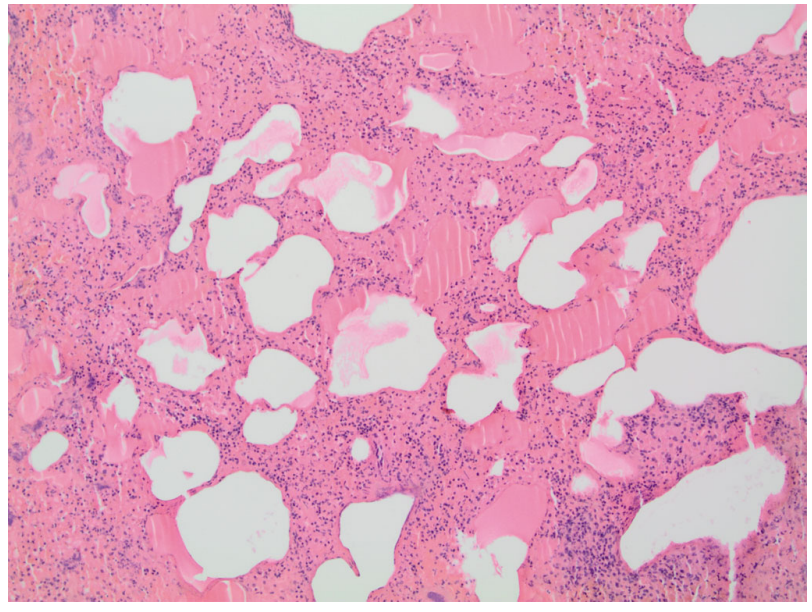

Fig. 6. Liver of a stranded adult female long-beaked common dolphin Delphinus capensis, demonstrating acute necrosis and edema with hemorrhage and gas bubble formation. The preservation of cells is not suggestive of autolysis. Magnification is $100 \times$

the intestines were observed. The eye revealed equivocal bubbles within vessels and lymphatics as well as small clear bubbles within the retina at the choroid and outer nuclear layers.

\section{Ancillary tests}

The gas abundance score was high, receiving a 10 on a scale of 1 to 10 . The average (mean $\pm \mathrm{SD}$ ) gas composition of sampled bubbles was $47.7 \pm 7.5 \% \mathrm{H}_{2}$, $26.8 \pm 5.6 \% \mathrm{~N}_{2}, 18.8 \pm 8.7 \% \mathrm{CO}_{2}$, and $6.7 \pm 1.3 \% \mathrm{O}_{2}$ (Table 1). $\mathrm{CH}_{4}$ was not detected in any of the samples. One sample was contaminated with atmospheric air (parietal peritoneum 2) and was not used in the calculation of averages.

Table 1. Composition (\%) of gas emboli sampled in a stranded adult female long-beaked common dolphin Delphinus capensis. Note that the parietal peritoneum 2 sample was air polluted and was therefore not used in the analysis

\begin{tabular}{|lcccr|}
\hline Sampling location & $\mathrm{H}_{2}$ & $\mathrm{O}_{2}$ & $\mathrm{~N}_{2}$ & $\mathrm{CO}_{2}$ \\
\hline Mesenteric vasculature 1 & 64.7 & 4.9 & 21.5 & 8.8 \\
Mesenteric vasculature 2 & 44.2 & 7.2 & 29.8 & 18.7 \\
Mesenteric vasculature 3 & 40.7 & 5.5 & 19.9 & 33.9 \\
Parietal peritoneum 1 & 45.6 & 6.7 & 25.5 & 22.1 \\
Parietal peritoneum 3 & 48.3 & 9 & 37.2 & 5.5 \\
Aorta vasculature 1 & 50.3 & 5.6 & 23.0 & 21.2 \\
Aorta vasculature 2 & 42.1 & 7.8 & 30.4 & 19.6 \\
Aorta vasculature 3 & 45.3 & 7 & 26.8 & 20.9 \\
Negative (air) & 0.0 & 20.30 & 79.67 & 0.3 \\
\hline
\end{tabular}


Anaerobic cultures of the lung, spleen, liver, bone marrow, and abdominal fluid all yielded pure cultures of Clostridium perfringens. Genotyping and toxin testing identified it as genotype A that was negative for enterotoxin and beta 2 toxins. Aerobic cultures did not yield any pathogenic organisms. A PCR test on a uterine swab was negative for Brucella sp.

\section{DISCUSSION}

Multiple diagnostic tools supported a thorough evaluation and diagnosis of Clostridium perfringens gas gangrene in this case study. CT, MRI, and gross examination revealed extensive widespread gas bubbles in the vasculature and organs. The identification of Gram-positive bacterial rods and tissue necrosis on histopathology, pure cultures of C. perfringens in multiple organs, PCR identification of toxin type $\mathrm{A}$, and a high $\mathrm{H}_{2}$ content in the gas bubbles indicates that $C$. perfringens propagated through the body, producing gas and alpha toxin, which led to tissue necrosis in multiple organs.

In the initial stage of the investigation, after diagnostic imaging revealed abundant vascular gas emboli similar to previous barotrauma cases (St. Leger et al. 2011), this was initially considered as a possible etiology. Obvious differences became evident after the gross exam, radiology, microbiology, histopathology, and gas composition results were complete. Not only was there an absence of patchy hemorrhage throughout the pulmonary parenchyma as was seen in barotrauma cases, but there was organ necrosis, parenchymal cavitations, bacteria, and a gas composition dissimilar to those cases. The ocular gas detected was also unusual, as it has only been seen to date in marine mammals drowned at depth (Moore et al. 2009). This finding in combination with the extensive volume and distribution of gas including intestinal and hepatic pneumatosis revealed an etiology distinct from the previously described gas bubble cases attributed to off-gassing or barotrauma.

The cavitations observed in this case are similar to the hepatic cavitations described in UK cetaceans. In those animals, no bacteria were cultured from 5 of 6 cavitated livers, and the 1 case in which C. perfringens was isolated was attributed to autolysis (Jepson et al. 2005). The etiology of those cavitations remains unknown, although the authors proposed off-gassing of supersaturated tissues or embolism of intestinal gas as possible causes. Our gross necropsy results mirror the 'copious amounts of gas present in the muscles, liver, and under the capsules of the kidney' that were found in a captive Tursiops with systemic clostridial gas gangrene (Buck et al. 1987, p. 488), with the exception that in our case necrosis was found in organs other than the muscle that was observed in that study.

Intravascular gas is a common finding in stranded cetaceans, although not typically in great abundance. The extensive bubbles (a score of 10 out of 10) in this freshly dead dolphin supports that these were an important pathological finding and did not originate from the process of decay. The uniqueness of such a high score is highlighted by a previous survey of gas accumulation in fresh stranded marine mammals where only 2 out of 38 specimens received a gas score higher than 5, viz. 7 and 9 (Bernaldo de Quirós et al. 2012b). Gas-producing bacteria such as Clostridium spp. must be on the differential diagnosis for intravascular gas in cetaceans. The presence of the alpha toxin associated with the isolated $C$. perfringens and the good tissue and cell preservation (Figs. 5 \& 6) support that this organism is the pathogen of the septicemia and not a postmortem contaminant.

The composition of the sampled bubbles further supports the gas-forming bacteria as the source of the intravascular and parenchymal gas. A composition of approximately $70-80 \% \mathrm{~N}_{2}$ and $20-30 \% \mathrm{CO}_{2}$ would be expected from animals affected by barotrauma or off-gassing of supersaturated tissues (Bernaldo de Quirós et al. 2012b). However, in this case, the average gas composition was distinctly different: $47.7 \pm 7.5 \% \mathrm{H}_{2}, 26.8 \pm 5.6 \% \mathrm{~N}_{2}, 18.8 \pm 8.7 \%$ $\mathrm{CO}_{2}$, and $6.7 \pm 1.3 \% \mathrm{O}_{2}$. A high $\mathrm{H}_{2}$ content typically indicates putrefaction (Bernaldo de Quirós et al. 2012b). During the decomposition process, destruction of tissues by the body's enzymes (autolysis) and microorganisms from the intestines and the environment (putrefaction) occurs (Vass 2001). Some of these microorganisms are fermentive $\mathrm{H}_{2}$-producing bacteria, which are restricted to a few genera, such as Clostridium and Enterobacter (Xing et al. 2008). In this case, the hydrogen was likely produced while the dolphin was alive, by the $C$. perfringens cultured from multiple organs and presumed to be the rodshaped bacterium associated with the gas margins identified on histopathology. This fermentive gasproducing bacterium can yield profuse amounts of $\mathrm{H}_{2}$ and $\mathrm{CO}_{2}$ to maintain an anaerobic environment (Rood \& Cole 1991). However, these organisms are not strict anaerobes and the $7 \% \mathrm{O}_{2}$ found in our samples would be compatible with their survival, as $30 \%$ $\mathrm{O}_{2}$ tension allows for free growth of these bacteria whereas $70 \%$ restricts their growth (Revis 2011). The gas composition in this case was unlike that of a $C$. septicum gas gangrene case in a human that was 
reported as $5.9 \% \mathrm{H}_{2}, 3.4 \% \mathrm{CO}_{2}, 74.5 \% \mathrm{~N}_{2}$, and $16.1 \% \mathrm{O}_{2}$ (Chi et al. 1995). Such high $\mathrm{CO}_{2}$ and $\mathrm{O}_{2}$ levels are often indicators of atmospheric air-polluted samples (Bernaldo de Quirós et al. 2012b). However, Chi et al. (1995) hypothesized that the high oxygen level in their case may have been due to oxygen inhalation by the patient.

Since $C$. perfringens is ubiquitous in the environment and common in the GI tract of marine mammals, there could have been 2 possible routes of entry for this organism. It is plausible that it entered through 1 of the multiple open skin lesions or became systemic from a localized GI tract or uterine infection. While there was no indication of a GI tract infection, the focally extensive area of damage in the liver is a plausible site of origin for the infection. In humans, $C$. perfringens can be found in the genital tract of healthy women but may multiply and cause infection following an abortion or prolonged labor (Dylewski et al. 1989). The regressing corpus luteum associated with a wider uterine horn in this dolphin suggests that it could have been recently pregnant. If this was the case, the lack of lactation would indicate that either fetal resorption or a stillbirth occurred, or that the calf did not survive long after birth. Thus, it is possible that $C$. perfringens propagated from either a hepatic/biliary infection or an endometritis. Whatever the origin of $C$. perfringens, it is clear that it propagated throughout the body of this dolphin and produced gas and alpha toxin, which caused the observed tissue necrosis. The cavitations in the liver and brain likely formed due to the compression of the tissue from the expanding gas. The intravascular gas resulted from bacterial production.

The thorough evaluation of this case was crucial to understanding the extent and etiology of the observed gas in this specimen. MRI and CT were critical to appreciating the distribution and abundance of gas, especially in areas not visible on gross examination (e.g. heart, subarachnoid space). Histopathology further identified clear spaces in organs, organ necrosis, and bacterial rods. Microbiology and molecular studies identified the bacteria as $C$. perfringens type A while the gas composition analysis supported this finding. Although gas accumulation appears to be a common finding in marine mammals (Moore et al. 2009, Bernaldo de Quirós et al. 2012b, Dennison et al. 2012), the cause for such findings varies. Case studies like this one provide valuable information to improve our ability to make correct diagnoses and to understand disease in marine mammal populations. This information is important for developing meaningful marine mammal management plans.
Acknowledgements. We thank Eric Archer, Brittany Hancock-Hanser, and Claire Surrey-Marsden for initial stranding response and CT logistical support, Jeff Hester for necropsy assistance, Sarena Sunico for CT coordination and imaging, and Sea World Laboratory staff. Aspects of this study were funded by NOAA Prescott Grant no. NA11NMF4390085 and NMFS Office of Protected Resources, Marine Mammal Health and Stranding Response Program. Thanks to Nick Kellar, Susan Chivers, and 3 anonymous reviewers for their helpful comments on earlier versions of the manuscript.

\section{LITERATURE CITED}

Aschfalk A, Müller W (2001) Clostridium perfringens toxin types in hooded seals in the Greenland Sea, determined by PCR and ELISA. J Vet Med Ser B 48:765-769

Bernaldo de Quirós Y, González-Díaz Ó, Saavedra P, Arbelo M and others (2011) Methodology for in situ gas sampling, transport and laboratory analysis of gases from stranded cetaceans. Sci Rep 1:193

Bernaldo de Quirós Y, González-Díaz Ó, Arbelo M, Andrada M, Fernández A (2012a) Protocol for gas sampling and analysis in stranded marine mammals. Protocol Exchange, doi: 10.1038/protex.2012.002

Bernaldo de Quirós Y, González-Díaz O, Arbelo M, Sierra E, Sacchini S, Fernández A (2012b) Decompression versus decomposition: distribution, quantity and gas composition of bubbles in stranded marine mammals. Front Physiol 3:177

Bernaldo de Quirós Y, González-Díaz O, Møllerløkken A, Brubakk A, Hjelde A, Saavedra P, Fernández A (2013) Differentiation at autopsy between in vivo gas embolism and putrefaction using gas composition analysis. Int $\mathrm{J}$ Leg Med 127:437-445

Buck JD, Shepard LL, Spotte S (1987) Clostridium perfringens as the cause of death of a captive Atlantic bottlenosed dolphin (Tursiops truncatus). J Wildl Dis 23:488-491

Caldwell DK, Caldwell MC (1985) Manatees - Trichechus manatus Linnaeus, 1758; Trichechus senegalensis Link, 1795 and Trichechus inunguis (Natterer, 1883). In: Ridgway SH, Harrison R (eds) Handbook of marine mammals, Book 3. The sirenians and baleen whales. Academic Press, London, p 33-66

Chi CH, Chen KW, Huang JJ, Chuang YC, Wu MH (1995) Gas composition in Clostridium septicum gas gangrene. J Formos Med Assoc 94:757-759

Cowan D, Walker W (1979) Disease factors in Stenella attenuata and Stenella longirostris taken in the eastern tropical Pacific yellowfin tuna purse seine fishery. Administrative Report. LJ-79-32C, Southwest Fisheries Science Center, National Marine Fisheries Service, La Jolla, CA

Danil K, Chivers SJ (2007) Growth and reproduction of female short-beaked common dolphins, Delphinus delphis, in the eastern tropical Pacific. Can J Zool 85:108-121

> Danil K, St. Leger JA (2011) Seabird and dolphin mortality associated with underwater detonation exercises. Mar Technol Soc J 45:89-95

> Dennison S, Moore MJ, Fahlman A, Moore K and others (2012) Bubbles in live-stranded dolphins. Proc R Soc Lond B Biol Sci 279:1396-1404

> Dylewski J, Wiesenfeld H, Latour A (1989) Postpartum uterine infection with Clostridium perfringens. Rev Infect Dis 11:470-473 
Fernández A, Edwards JF, Rodríguez F, Espinosa de los Monteros A and others (2005) 'Gas and fat embolic syndrome' involving a mass stranding of beaked whales (Family Ziphiidae) exposed to anthropogenic sonar signals. Vet Pathol 42:446-457

Greenwood AG, Taylor DC (1978) Clostridial myositis in marine mammals. Vet Rec 103:54-55

> Griffin EI, Goldsberry DG (1968) Notes on the capture, care and feeding of the killer whale Orcinus orca at Seattle Aquarium. Int Zoo Yearb 8:206-208

Hamilton RWTE (2003) Decompression practice. In: Brubakk AO, Neuman TS (eds) Bennett and Elliott's physiology and medicine of diving, 5th edn. Saunders, London, p 455-450

Hart GB, Lamb RC, Strauss MB (1983) Gas gangrene: I. A collective review. J Trauma Inj Infect Crit Care 23: 991-1000

Hirsh DC, Biberstein EL (2004) Clostridium. In: Hirsh DC, MacLachlan NJ, Walker RL (eds) Veterinary microbiology, 2nd edn. Blackwell Publishing, Ames, IA, p 198-214

Jepson PD, Arbelo M, Deaville R, Patterson IAP and others (2003) Gas-bubble lesions in stranded cetaceans. Nature 425:575-576

> Jepson PD, Deaville R, Patterson IAP, Pocknell AM and others (2005) Acute and chronic gas bubble lesions in cetaceans stranded in the United Kingdom. Vet Pathol 42:291-305

Jores J, Derocher AE, Staubach C, Aschfalk A (2008) Occurrence and prevalence of Clostridium perfringens in polar bears from Svalbard, Norway. J Wildl Dis 44:155-158

McDonel JL (1980) Clostridium perfringens toxins (type A, B, C, D, E). Pharmacol Ther 10:617-655

Meer RR, Songer JG (1997) Multiplex polymerase chain reaction assay for genotyping Clostridium perfringens. Am J Vet Res 58:702-705

Moore MJ, Early GA (2004) Cumulative sperm whale bone damage and the bends. Science 306:2215

Moore MJ, Bogomolni AL, Dennison SE, Early G and others (2009) Gas bubbles in seals, dolphins, and porpoises entangled and drowned at depth in gillnets. Vet Pathol 46:536-547

Piantadosi CA, Thalmann ED (2004) Pathology: whales, sonar and decompression sickness. Nature 428:716-718

Editorial responsibility: Michael Moore,

Woods Hole, Massachusetts, USA
Quinn PJ, Markey BK, Leonard F, FitzPatrick E, Fanning S, Hartigan P (2011) Veterinary microbiology and microbial disease. John Wiley \& Sons, Chichester

Revis DR Jr (2011) Clostridial gas gangrene. Available at http://emedicine.medscape.com/article/214992-overview \#a0104 (accessed 22 January 2012)

$>$ Rood JI, Cole ST (1991) Molecular genetics and pathogenesis of Clostridium perfringens. Microbiol Rev 55:621-648

Saukko PJ, Knight B (2004) Knight's forensic pathology. Oxford University Press, New York, NY

Shaw A, Cooperman A, Fusco J (1967) Gas embolism produced by hydrogen peroxide. N Engl J Med 277:238-241

- Siebert U, Wünschmann A, Weiss R, Frank H, Benke H, Frese K (2001) Post-mortem findings in harbour porpoises (Phocoena phocoena) from the German North and Baltic Seas. J Comp Pathol 124:102-114

> Siebert U, Wohlsein P, Lehnert K, Baumgärtner W (2007) Pathological findings in harbour seals (Phoca vitulina): 1996-2005. J Comp Pathol 137:47-58

St. Leger J, Danil K, Dennison S, Scadeng M and others (2011) Pathology of barotrauma in long-beaked common dolphins (Delphinus capensis). Proc 19th Biennial Conference on the Biology of Marine Mammals, Tampa, FL, p 281

Sweeney JC, Ridgway SH (1975) Common diseases of small cetaceans. J Am Vet Med Assoc 167:533-540

Van Bonn WG, Ridgway SH, Williams BH (1995) Chronic refractory emesis associated with a colonic lesion in a California sea lion (Zalophus californianus). J Zoo Wildl Med 26:286-292

Vass AA (2001) Beyond the grave - understanding human decomposition. Microbiol Today 28:190-193

Walsh MT, Thomas LA, Songer JG, Campbell TW, Tucker LS (1994) Clostridium perfringens isolates from cetaceans. Proc 25th annual workshop of the International Association for Aquatic Animal Medicine, Vallejo, CA, p 95

> Xing D, Ren N, Rittmann BE (2008) Genetic diversity of hydrogen-producing bacteria in an acidophilic ethanol$\mathrm{H}_{2}$-coproducing system, analyzed using the [Fe]-hydrogenase gene. Appl Environ Microbiol 74:1232-1239

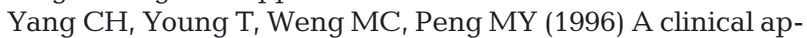
proach to gas-forming soft tissue infections: report of 14 cases and review of the literature. J Med Sci 16:340-348

Submitted: February 12, 2014; Accepted: June 19, 2014

Proofs received from author(s): September 16, 2014 